\title{
Canalicular adenoma of the upper lip: a short case study
}

\author{
Ugo Ordioni ${ }^{1,2, *}$, Fabrice Campana ${ }^{2}$, Jean-Hugues Catherine ${ }^{2}$, Romain Lan $^{2}$ \\ ${ }^{1}$ Centre Massilien de la Face, Marseille, France \\ 2 Service d'Odontologie, CHU Timone, Marseille, France \\ *Correspondence: ugo.ordioni@gmail.com
}

(Received: 22 July 2017, accepted: 8 September 2017)

Keywords:

salivary glands / salivary gland

neoplasms / adenoma / lip

\begin{abstract}
Introduction: Canalicular adenoma (CA) is a benign tumor that develops in the accessory salivary glands. Observation: We reported a case of CA of the upper lip in a 61-year-old man. Discussion: The clinical diagnosis of CA is difficult, and a lot of possible differential diagnoses exist, including benign or malignant salivary tumors. Thus, the diagnosis may be challenging and must rely on histological examination findings. The treatment is surgical in nature and the prognosis is excellent.
\end{abstract}

\section{Observations}

A 61-year-old man consulted for a lesion of the upper lip which had appeared over the course of 2 years. He was asthmatic, and he was under treatment with nasal beclomethasone dipropionate spray and bilastin.

There was no functional pain or signs. A clinical examination revealed a mucosal nodule of $1.5 \mathrm{~cm}$ from the upper left lip (Fig. 1). The nodule was hard in consistency and was mobile. The mucous membrane covering the lesion was normal. There was no associated lymphadenopathy.

The lesion was resected under local anesthesia. Macroscopical$l y$, the tumor was well demarcated and was yellowish in color. A histological examination carried out in the operating room showed a CA with epithelial proliferation, which was organized in canals and in septa, consisting of regular tall cylindrical cells without any cellular atypia. The stroma was loose and fibrohyaline in nature. Immunohistochemistry (AE1-AE3) emphasized epithelial proliferation (Fig. 2). The tumor was negative for P63. No recurrence was identified in the 3 months after resection.

\section{Discussion}

CA is a benign tumor of the salivary glands. It is in terms of frequency, it is the third-most common salivary gland tumor after, pleomorphic adenoma and mucoepidermoid carcinoma [1]. However, it is still rare and represents $1 \%$ of all salivary tumors and $4 \%$ of the tumors affecting the accessory salivary glands [2]. Its peak incidence is in the seventh decade of life. The average age of occurrence is 65 years, and it is not frequently found in patients aged $<50$ years. There has never been a case in a child [1]. The sex ratio (F/M) is 1.8:8 [2]. It is most frequently located on the upper lip ( $80 \%$ CA cases). The buccal mucosa is more rarely affected ( $9.25 \%$ of tumors).
The major salivary glands are very rarely affected. Multiple cases of CA have been described [3].

Clinically, CA occurs as an asymptomatic mucosal nodule that rarely exceeds $2 \mathrm{~cm}$ in size. The overlying mucosa is normal and not ulcerated, but it can sometimes have a bluish color [2]. Their growth is slow.

Macroscopically, the tumor is well demarcated and may or may not be encapsulated, and may have a lumpy appearance. The classical histological description shows a double row of cylindrical cells forming cords in a loose stroma (Fig. 2). These double rows are tight or separate forming canaliculi with a tree-like appearance, or cysts or channels when the section is perpendicular. The cells are in usually cylindrical but can also be cuboidal, and the number of mitoses is low. The stroma is paucicellular and rich in blood capillaries. Immunohistochemistry shows positivity for anti-cytokeratin, anti-vimentin, and anti-S100 antibodies and negativity for smooth actin, calponin, P63, and E-cadherin [1]. In $9 \%$ of cases, the CA is multifocal $[1,4]$.

Differential diagnosis is made with a mucoid cyst, vascular tumor, phleboliths, lipoma, or another salivary gland tumor, including basal cell adenoma, low-grade adenocarcinoma, and cystic adenoid carcinoma. The distinction between these salivary gland tumors and multifocal CA can be difficult, the immunohistochemistry is useful for the diagnosis $[4,5]$.

The treatment is always surgical in nature. The prognosis is good, and no malignant transformation has ever been described in the literature. Recurrences are rare but are more frequent in multifocal CA.

\section{Conflicts of interests}

The authors declare that they have no conflicts of interest in relation to this article. 


\section{SHORT CASE REPORT}

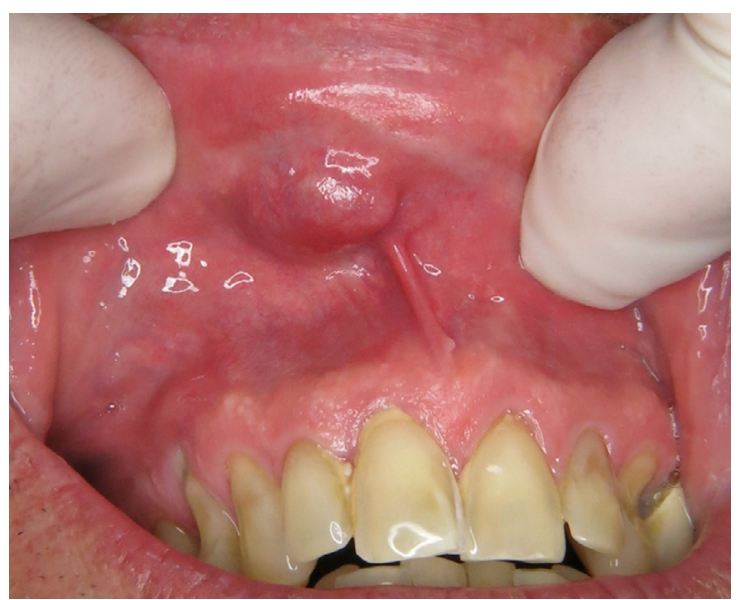

Fig. 1. Clinical aspect of the lesion.

\section{References}

1. Thompson LDR, Bauer JL, Chiosea S, McHugh JB, Seethala RR, Miettinen M, Müller S. Canalicular adenoma: a clinicopathologic and immunohistochemical analysis of 67 cases with a review of the literature. Head Neck Pathol 2015;9:181-195.

2. Barnes L, Eveson J, Reichart P, Sidransky D. Pathology and genetics of tumors of the head and neck. World Health Organization classification of tumors, Lyon: IARC Press, 2001.

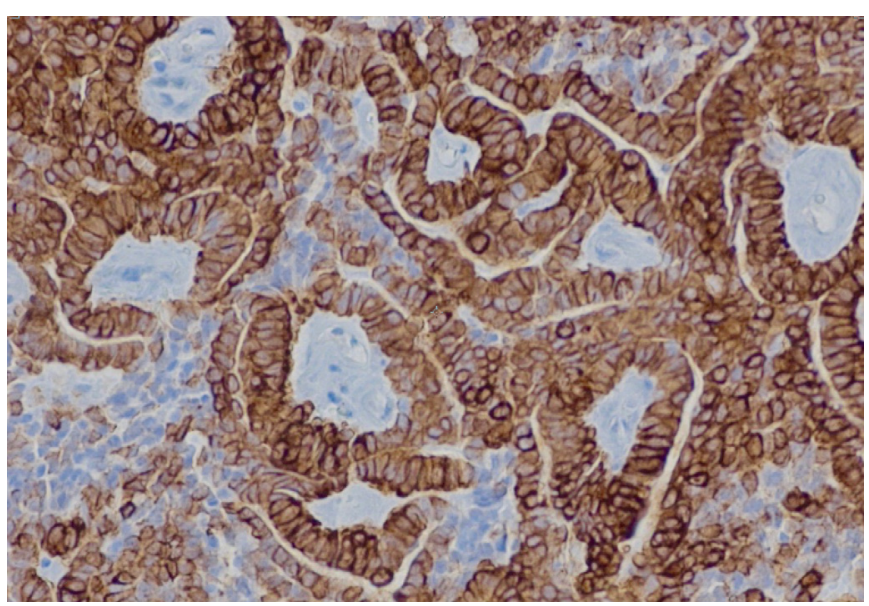

Fig. 2. Microscopic aspect of the lesion. Double row of high cylindrical cells forming cords. Intense expression of pancytokeratin (AE1/AE3).

3. Tyralik D, Dzierwa-Gawron A, Rys J. Canalicular adenoma of the upper lip. Metachronous (multifocal) canalicular adenoma of the upper lip: a case report of an unusual finding. Pol J Pathol 2013;64:71-74.

4. Samar ME, Avila RE, Fonseca IB, Anderson W, Fonseca GM, Cantín M. Multifocal canalicular adenoma of the minor labial salivary glands. Int J Clin Exp Pathol 2014;7:8205-8210.

5. Sivolella S, Valente M, De Biagi M, Mazzoleni SS, Tellini E. Canalicular adenoma immunoprofile: a case report. Gerodontology 2014;31:320-324.

Med Buccale Chir Buccale 2017:23;190-191

(C) The authors, 2017

This is an Open Access article distributed under the terms of the Creative Commons Attribution License (http://creativecommons.org/licenses/by/4.0), which permits unrestricted use, distribution, and reproduction in any medium, provided the original work is properly cited. 